\title{
Management of Hypertensive Disease During Pregnancy
}

\section{INTRODUCTION}

Hypertension in pregnancy is an important cause of direct maternal deaths in Sri Lanka. Early identification, aggressive and intensive treatment of its complications is important in reducing the resulting morbidity and mortality.

\section{DEFINITIONS}

\section{Chronic Hypertension}

Women with pre-existing hypertension or hypertension detected before 20th week of gestation in the absence of trophoblastic disease and persisting more than 42 days post partum.

\section{Gestational Hypertension}

\section{A) Pregnancy Induced Hypertension:}

Hypertension unaccompanied by proteinuria developing after 20 weeks of gestation and resolving within 42 days of delivery.

\section{B) Pre-eclampsia:}

Pregnancy induced hypertension associated with significant proteinuria $(300 \mathrm{mg} / 1$ or $500 \mathrm{mg} / 24$ hours or dipstick $2+$ or more).

\section{Severe Pre-eclampsia:}

Defined as pre-eclampsia with severe hypertension and/or with symptoms, and/or biochemical and/or haematological impairment.

The clinical features of severe pre-eclampsia (in addition to hypertension and proteinuria) are:

- Severe headache

- Visual disturbances such as blurring of vision or flashing before eyes, scotomas

- $\quad$ Epigastric or hypochondria I pain and/or nausea \& vomiting

- Clonus (3 beats or more)

- Papilloedema

- Liver tenderness

- Oliguria (less than $400 \mathrm{ml}$ per day or $0.5 \mathrm{mg} / \mathrm{Kg} / \mathrm{hour}$ over a 4 hour period)

- Platelet count falling to below $100 \times 106 / 1$

- Abnormal liver enzymes (ALT or AST rising to above 70IU/I)

- HELLP syndrome

\section{Severe Hypertension:}

Defined as systolic blood pressure" $160 \mathrm{mmHg}$ and/or diastolic blood pressure d $10 \mathrm{mmHg}$.

\section{Eclampsia:}

Defined as the development of convulsions and/or unexplained coma during pregnancy or postpartum in patients with features of preeclampsia.

\section{SCREENING FOR HYPERTENSION DURING PREGNANCY}

Blood pressure must be measured in every clinic visit by a Medical Officer and results recorded and plotted in the pregnancy record.

Proteinuria must be tested for at every clinic visit.

If blood pressure is more than $140 / 90 \mathrm{mmHg}$ on two occasions at least 2 hours apart, refer for specialist care.

\section{PREVENTION OF HYPERTENSIVE DISORDERS IN PREGNANCY}

Advise women at high risk of pre-eclampsia to take $75 \mathrm{mg}$ of aspirin daily from 12 weeks until delivery of the baby. Women at high risk are:

\section{Those with anyone of the following risk factors:}

- Hypertensive disease during a previous pregnancy

- Chronic kidney disease

- Autoimmune disease such as systemic lupus erythematosus or antiphospholipid syndrome

- $\quad$ Type lor type 2 diabetes

- Chronic hypertension

- Multiple pregnancy

Or, any TWO or more of the following

- $\quad$ First pregnancy

- Age 40 years or older

- Pregnancy interval of more than 10 years

- Body mass index (BMI) of $35 \mathrm{~kg} / \mathrm{m}^{\prime}$ or more at first visit

- Family history of preeclampsia

Contra indications such as allergy, gastritis, peptic ulcer disease must be taken into account.

Advice women who have the above risk factors to ensure a higher intake of calcium to achieve a daily intake of at least $1000 \mathrm{mg}$ taking into account the average intake by Sri 
Lankan women the recommended supplementation level is $600 \mathrm{mg}$.

\section{MANAGEMENT OF CHRONIC HYPERTENSION}

Women with chronic hypertension must be managed in specialist units. Anticipate the development of superimposed pre-eclampsia in these women. This combination adds risks to both mother and baby. ACE inhibitors should be discontinued in women who are planning pregnancy and its use avoided during pregnancy.

\section{TREATMENT OF MILD TO MODERATE HYPERTENSION}

Since there is no consensus on the value of treating mild to moderate hypertension, this guideline will not address this issue.

\section{MANAGEMENT OF SEVERE PRE-ECLAMPSIA}

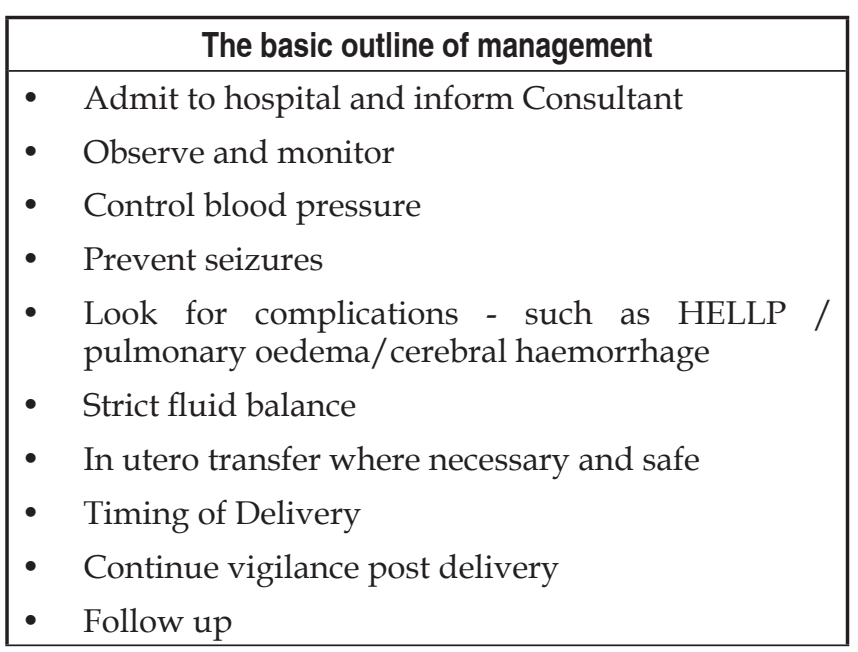

\subsection{General Considerations}

- Severe preeclampsia is a life threatening condition.

- The only known cure is delivery of the baby.

- The immediate task is to determine the urgency to effect delivery.

- Stabilization of the mother's condition within an acceptable time frame prevents maternal complications and may improve fetal condition.

- The management has to be individualized depending on the clinical condition and available resources.

- The dangers will continue into the immediate postpartum period.

\subsection{Specific Management}

Admit women who have severe preeclampsia and inform the Consultant.
Treat hypertension if:

- $\quad$ Systolic blood pressure $\geq 160 \mathrm{mmHg}$, or if

- Diastolic blood pressure $\geq 110 \mathrm{~mm} \mathrm{Hg}$, or if

- Mean arterial pressure $\geq 125 \mathrm{mmHg}$

Aim to maintain blood pressure at around 130-140/90-100 $\mathrm{mmHg}$.

The main cause of maternal death in severe preeclampsia is poorly controlled systolic hypertension causing cerebral haemorrhage.

A rapid fall in maternal blood pressure as a result of antihypertensive treatment may cause fetal heart rate abnormalities \& compromise especially in growth restricted/compromised fetuses.

Where resources allow, it is recommended to monitor fetal heart with continuous CTG during and for 60 minutes after commencing anti-hypertensive therapy.

Aim to stabilize blood pressure before delivery.

\subsubsection{Anti-hypertensive drugs}

Oral anti hypertensives may be used when the blood pressure is $<180 / 110 \mathrm{mmHg}$. Blood pressure must be monitored at 1S-minute intervals and intravenous anti hypertensives resorted to in case of an adequate response is not obtained within 30 minutes.

The commonly used antihypertensive drugs for acute control are given below. One or the other may be used depending on availability and familiarity.

\subsubsection{Labetalal arally ar intravenausly}

This should be avoided in women with a history of bronchial asthma.

- $200 \mathrm{mg}$ orally stat (only if blood pressure is $<180 / 110 \mathrm{~mm} \mathrm{Hg}$ )

- $\quad$ repeated hourly for up to 4 hours

or

- $20 \mathrm{mg}$ IV over two minutes

- $\quad$ Record blood pressure after 10 minutes.

- If either value is still above $160 \mathrm{~mm} \mathrm{Hg}$ systolic and/ or $110 \mathrm{mmHg}$ diastolic, give $40 \mathrm{mg}$ iv over 2 minutes.

- Record blood pressure after 10 minutes.

- If the blood pressure is still above $160 \mathrm{~mm} \mathrm{Hg}$ systolic and/or $110 \mathrm{mmHg}$ diastolic, give hydralazine $10 \mathrm{mg}$ iv. For instructions regarding giving a fluid bolus with i.v. hydralazine, see the next section of this guideline.

- If the blood pressure is still above $160 \mathrm{~mm} \mathrm{Hg}$ systolic and/or $110 \mathrm{mmHg}$ diastolic, start an IV infusion of labetolol, starting at $40 \mathrm{mg} /$ hour, doubling the dose at half hourly intervals as required to a maximum total of $160 \mathrm{mg}$ /hour. 
- Where these measures fail, the mother must be moved to a high-dependency area or an intensive care unit.

If blood pressure is controlled by the above, continue monitoring the blood pressure at $1 \mathrm{~S}$ minute intervals for I hour and at 30 minute intervals thereafter.

Additional bolus doses as described above may be administered if the blood pressure increases above 160 $\mathrm{mm} \mathrm{Hg}$ systolic and/or $110 \mathrm{mmHg}$ diastolic.

\subsubsection{Hydralazine intravenausly:}

- 5 - $10 \mathrm{mg}$ IV bolus over 2 minutes.

- This must be accompanied by a fluid bolus of $5 \mathrm{ml} / \mathrm{kg}$ of $0.9 \%$ sodium chloride or Ringer lactate solution over $30 \mathrm{~min}$, started at the same time as iv hydralazine (this helps vasodilatation \& prevents drastic hypotension). This should not be used in the presence of pulmonary oedema.

- Record blood pressure at 15-minute intervals.

- Repeat boluses of 5 - $10 \mathrm{mg}$ IV after a 15-minute interval may be given if necessary up to a maximum of $20 \mathrm{mg}$ (the effect of a single dose can last up to 6 hours).

- If the response to above doses is inadequate, give labetolol bolus doses as described above.

- If no lasting effect with above boluses, consider an infusion of hydralazine $2.0 \mathrm{mg} /$ hour increasing by $0.5 \mathrm{mg} /$ hour as required $(2-20 \mathrm{mg} /$ hour usually required).

\subsubsection{Oral Nifedipine}

- Oral nifedipine may be used where the blood pressure is $<180 / 110 \mathrm{~mm} \mathrm{Hg}$, in asymptomatic patients.

- Give $10 \mathrm{mg}$ orally.

- Repeat at 20-minute intervals up to a maximum of 40 $\mathrm{mg}$.

- If there is no response proceed to intravenous labetalol or hydralazine.

\subsubsection{Preventian af canvulsians}

\section{Magnesium sulphate}

- Magnesium sulphate is the anticonvulsant of choice.

- It should be given to any woman with features of impending/imminent eclampsia (presence of clonus, severe headache, visual disturbances, and dizziness) .

- The loading dose may be given even when the status of renal function is uncertain, since it is unlikely that toxic levels of magnesium could be reached with this dose alone.

- Give loading dose of 4 G IV over 10 minutes. There are two methods of giving magnesium sulphate intravenously.
- Diluted to a total volume of $20 \mathrm{ml}$ with $0.9 \%$ sodium chloride solution, given via an infusion pump or 'manually'.

- Diluted to a total volume of $80 \mathrm{ml}$ with $0.9 \%$ sodium chloride solution via a burette

- Immediately after the loading dose, start infusion of 1 G IV per hour. Continue this infusion for at least 24 hours after delivery.

- Where there are difficulties with intravenous access, magnesium sulphate may be administered intramuscularly. Give $5 \mathrm{G}$ deep intramuscularly into each buttock with $1 \mathrm{ml}$ of $2 \%$ lignocaine in the same syringe.

- If intramuscular magnesium sulphate is continued as maintenance therapy, give 5G to alternate buttocks 4 hourly, with $1 \mathrm{ml}$ of $2 \%$ lignocaine in the same syringe.

- Monitor the mother to ensure hourly urine output of $30 \mathrm{ml}$ per hour, respiratory rate $>16$ / minute, oxygen saturation $>90 \%$ and presence of patellar reflexes.

- $\quad$ These should be recorded every 30 minutes.

- Should signs of toxicity appear, the antidote is calcium gluconate, $1 \mathrm{G}$ intravenously ( $10 \mathrm{ml}$ of $10 \%$ solution), given over 10 minutes.

- Magnesium sulphate may be used safely in women who have previously received nifedipine.

\subsubsection{Fluid Balance}

- Restrict total fluid intake to $80 \mathrm{ml}$ per hour.

- Accurate recording of fluid balance is essential.

- Selective colloid expansion may be necessary prior to pharmacological vasodilatation to prevent maternal hypotension and fetal compromise or in oliguria with a low central venous pressure.

- The volumes of all drugs administered must be taken into account and appropriate reduction of the volume of crystalloids must be made.

- Colloid (e.g. Hetastarch) should be administered only after discussion with the anaesthetist.

- Diuretics must be restricted to specific instances only e.g. for women with pulmonary oedema.

- Avoid non-steroidal analgesia until fluid recovery.

\subsubsection{In utero/neonatal transfer}

- If a Unit does not have access to HDU/ICU or is unable to cope with maternal complications, or with maturity of the baby, it may be appropriate to consider antenatal transfer of the mother.

- However, maternal safety must not be jeopardised and each case should be considered on its clinical merits.

- Steps must be taken to bring down blood pressure 
from very high levels (e.g. using nifedipine

- Women with imminent/impending eclampsia must be administered a loading dose of magnesium (1M or IV) before transfer (see 6.2.2)

- It is recommended that where possible telephone advice is obtained from the relevant specialist unit before transfer.

- The patient must be accompanied by a member of staff who is capable of dealing with a seizure while the patient in transit. The required drugs and equipment must be made available.

- Full details of the case, including treatment given should accompany the patient.

\subsubsection{Delivery}

- Urgency of delivery depends on the maternal and fetal conditions.

- Either caesarean section or induction of labour is appropriate depending on the urgency and favourability of the cervix.

- Institute adequate pain relief. Severe preeclampsia is not a contraindication for opioid or epidural anesthesia (see below). It is accepted that epidural anesthesia helps to bring down the blood pressure.

- Spinal or epidural anaesthesia is safe in the presence of a platelet count $>80, \mathrm{OOO} / \mathrm{dl}$.

- Maternal condition should be optimised before delivery.

- It is inappropriate to deliver an unstable mother for foetal reasons.

- Ergometrine should not be used during the third stage.

\subsubsection{Post-delivery}

- Maintain vigilance as a high proportion of eclamptic seizures occur after delivery.
- High dependency care should be provided as clinically indicated.

- Continue close monitoring, including fluid balance, platelets, liver enzymes and creatinine until they have returned to normal values.

- Magnesium sulphate if started should be continued for 24 hours after the delivery or after the last fit, whichever is later.

- Review anti-hypertensive medication as indicated. Some may need to continue oral medication for a few weeks. Methyldopa is best avoided following delivery because of its tendency to cause depression.

\subsubsection{Follow up}

- Inform Public Health Midwife and/or Medical Officer of Health.

- $\quad$ Review in 2 weeks (instead of 4 weeks) if discharged on antihypertensives.

- Depending on the clinical picture, some patients may need:

- Long term follow up for blood pressure

- Hematological investigations for conditions such as anti-phospholipid syndrome, thrombophilia

- Debrief the patient.

- Advice preconceptual counseling \& check prior to the next pregnancy.

- Women may be advised regarding the risk of developing hypertensive disease in a future pregnancy as follows:

- Risk of gestational hypertension - 53\% (1 in 2)

- Risk of preeclampsia - 16\% (1 in 6)

- Risk of preeclampsia if she had severe hypertension or HELLP syndrome or eclampsia or the birth occurred before 34 weeks - 25\% (1 in $4) ; \& 55 \%$ ( 1 in 2 ) if the birth occurred before 28 weeks gestation. 